JPPKMI 2 (1) (2021) 60-66
JURNAL PENELITIAN DAN PENGEMBANGAN
KESEHATAN MASYARAKAT INDONESIA
Jttps://journal.unnes.ac.id/sju/index.php/jppkmi

\title{
Analisis Perencanaan Obat di UPTD Farmasi Dinas Kesehatan Kota Depok
}

\author{
Dhea Keyle Fortunandha ${ }^{1}$, Arih Diyaning Intiasari ${ }^{2}$, Arif Kurniawan ${ }^{2}$
}

${ }^{1}$ Public Health Student of Jenderal Soedirman University, Indonesia

${ }^{2}$ Public Health Lecturer of Jenderal Soedirman University, Indonesia

\section{Info Artikel}

Sejarah Artikel:

Diterima 18 April 2021

Disetujui 9 Juni 2021

Dipublikasi 23 Juni 2021

\section{Keywords:}

Perencanaan, Obat, Unit

Pelayanan Teknis

Kefarmasian, Dinas

Kesehatan Pemerintah

URL:

https://iournal.unnes.ac.i $\mathrm{d} / \mathrm{sju} /$ index.php/ippkmi /article/view/47251

\begin{abstract}
Abstrak
Penemuan obat kadaluarsa merupakan dampak negatif yang dialami oleh Unit Pelayanan Teknis Kefarmasian Dinas Kesehatan Pemerintah Kota Depok, sehingga dapat diduga bahwa perencanaan obat belum dilakukan dengan baik. Penelitian ini merupakan penelitian kualitatif dengan desain studi kasus. Penelitian ini dilakukan di Unit Pelayanan Teknis Kefarmasian Dinas Kesehatan Pemerintah Kota Depok dengan jumlah informan 8 orang. Analisis data yang digunakan adalah analisis isi. Analisis perencanaan obat pada Unit Pelayanan Teknis Kefarmasian Dinas Kesehatan Pemerintah Kota Depok menunjukkan bahwa keterbatasan sumber daya manusia yang belum cukup mengetahui proses penghitungan kebutuhan obat, pencatatan dan pelaporan logistik obat yang dilakukan secara manual menjadi kendala utama. dalam penggunaan data untuk perencanaan obat, pemilihan jenis obat dan perhitungan kebutuhan obat belum sepenuhnya sesuai dengan pedoman. Perencanaan obat tidak dilakukan secara maksimal karena adanya obat kadaluarsa dan kekosongan stok obat yang menyebabkan hasil perencanaan tidak sesuai dengan yang diharapkan sehingga perlu dilakukan monitoring dan evaluasi ketersediaan obat. Perencanaan obat yang dilakukan oleh Unit Pelayanan Teknis Kefarmasian Dinas Kesehatan Pemerintah Kota Depok belum sepenuhnya sesuai dengan juknis pengadaan obat juga terdapat obat kadaluarsa dan kekosongan stok obat yang menyebabkan hasil perencanaan tidak sesuai dengan yang diharapkan.
\end{abstract}

\begin{abstract}
The findings of expired drugs is a negative impact experienced by the Pharmaceutical Technical Service Unit of Government Health Department in Depok, so it can be assumed that drug planning has not been carried out properly. This research is a qualitative research with a case study design. This research was conducted at the Pharmaceutical Technical Service Unit of Government Health Department in Depok with 8 informants. The data analysis used was content analysis. Analysis of drug planning at the Pharmaceutical Technical Service Unit of Government Health Department in Depok shows that limited human resources do not yet know enough about the process of calculating drug needs, recording and reporting drug logistics which is done manually to be the main obstacle in using data for drug planning, selecting types of drugs and calculating drug needs not completely according to the guidelines. Drug planning is not done optimally because there are expired drugs and drug stock vacancies which cause the planning results are not as expected so it is necessary to monitor and evaluate the availability of drugs. Drug planning carried out by the Pharmaceutical Technical Service Unit of Government Health Department in Depok is not fully in accordance with the technical guidelines for drug procurement also there are expired drugs and drug stock vacancies which cause the planning results are not as expected.
\end{abstract}

(C) 2021 Universitas Negeri Semarang

$凶$ Alamat korespondensi:

J1. DR. Soeparno No.61, Karang Bawang, Purwokerto Wetan,

Kec. Purwokerto Tim., Kabupaten Banyumas, Jawa Tengah 53111

E-mail: $\underline{\text { dheakevlef(g.gmail.com }}$ 


\section{PENDAHULUAN}

Obat memegang peran yang penting dalam pelayanan kesehatan karena obat merupakan salah satu sarana untuk meningkatkan derajat kesehatan. Keberadaan obat merupakan kondisi pokok yang perlu terjaga ketersediaannya, maka pengelolaan yang benar, efektif dan efisien sangat diperlukan oleh petugas pengelola obat baik di Pusat, Provinsi, maupun Kabupaten/Kota (Kemenkes RI 2010).

Tenaga Kefarmasian sebagai salah satu sumber daya manusia kesehatan pemberi pelayanan kesehatan kepada masyarakat mempunyai peranan penting karena terkait langsung dengan pemberian pelayanan kefarmasian. Rasio apoteker di Kota Depok tahun 2018 sebesar 10,26 per 100.000 penduduk, sedangkan target rasio apoteker adalah 11,4 per 100.000 penduduk. Hal ini dikatakan bahwa apoteker di Kota Depok masih kurang. Selain itu, rasio tenaga teknis kefarmasian sebesar 21,71 per 100.000 penduduk sedangkan target rasio kebutuhan tenaga teknis kefarmasian sebesar 22,8 per 100.000 penduduk yang berarti bahwa tenaga teknis kefarmasian di Kota Depok juga masih kurang. Kurangnya Sumber Daya Manusia (SDM) di bidang farmasi ini dapat memungkinkan terjadinya ketidaksesuaian perencanaan obat dengan pedoman teknis pengadaan obat publik dan perbekalan kesehatan untuk pelayanan kesehatan dasar (Profil Kesehatan Kota Depok 2019; Lubis 2017).

Hasil survey pendahuluan diketahui bahwa terdapat permasalahan salah satunya terkait obat kedaluwarsa yang dihadapi di UPTD Farmasi Dinas Kesehatan Kota Depok. Berdasarkan data pemusnahan obat per 23 Juli 2020 terdapat 669.114 obat kedaluwarsa dengan nominal sebesar $\mathrm{Rp} \quad 432.472 .945$ perlu dimusnahkan. Jika dibandingkan dengan penelitian yang dilakukan oleh Ihsan dkk (2015) mengenai evaluasi pengelolaan obat di Instalasi Farmasi Rumah Sakit Umum Daerah Kabupaten Muna terdapat sebanyak 17 item obat kedaluwarsa dengan nominal sebesar $\mathrm{Rp}$
6.591.654. Penelitian lain dilakukan oleh Boku dkk (2019) mengenai evaluasi perencanaan dan distribusi obat program di Dinas Kesehatan Provinsi Sulawesi Tenggara terdapat sebanyak 3 item obat kedaluwarsa dengan nominal sebesar $\mathrm{Rp}$ 1.890.395. Hal tersebut dapat diasumsikan bahwa terdapat cukup banyak obat kedaluwarsa di UPTD Farmasi Dinas Kesehatan Kota Depok yang dipengaruhi oleh perencanaan obat yang kurang baik.

\section{METODE}

Jenis penelitian ini adalah penelitian kualitatif dengan desain penelitian studi kasus agar peneliti dapat menggali informasi yang mendalam dan memperoleh cakupan yang lebih luas tentang perencanaan obat. Lokasi penelitian berada di UPTD Farmasi Dinas Kesehatan Kota Depok pada bulan November s.d. Desember 2020. Subyek penelitian diambil dengan pendekatan purposive sampling dengan jumlah informan sebanyak 8 orang yang terdiri dari UPTD Farmasi (3 orang), Pengelola Obat Puskesmas (3 orang), Penanggungjawab Program Kesehatan Jiwa Dinas Kesehatan Kota Depok (1 orang), Penanggungjawab Program Kesehatan Jiwa Puskesmas Pancoran Mas (1 orang). Analisis data yang digunakan adalah content analysis.

\section{HASIL DAN PEMBAHASAN}

\section{Sumber Daya Manusia}

Sumber daya manusia perencana obat di UPTD Farmasi dibentuk dalam suatu struktur yang terkoordinasi yakni Tim Perencana Obat Terpadu (TPOT) dengan dibuktikan oleh SK Kepala Dinas Kesehatan Nomor 440/0052/KPTS/Dinkes/2020 tentang penetapan tim perencana obat dan alat kesehatan terpadu pada Dinas Kesehatan Kota Depok. Namun dalam pelaksanaan perencanaan obat, sumber daya manusia yang ada belum pernah mengikuti pelatihan terkait perencanaan obat kepada SDM Perencana Obat. Disamping itu ketersediaan SDM kefarmasian di Puskesmas khususnya dalam 
perencanaan obat dirasa masih belum mencukupi. SDM yang dirasa belum mencukupi dikarenakan selama pandemi COVID-19 beban kerja dari SDM kesehatan meningkat, khususnya SDM pengelola obat. Beban kerja SDM pengelola obat yang meningkat membuat SDM kelelahan sehingga SDM tersebut melakukan kelalaian dalam pekerjaannya sehingga menghambat proses perhitungan kebutuhan obat karena memerlukan waktu untuk revisi RKO. Berikut kutipan wawancaranya:

"Saya juga belum pernah pelatihan tentang perencanaan obat." (PJPD)

"[...] Jadi kendalanya ya disitu sih, (lelah) yaa [...] Banyak yang dikerjakan juga." (POPGS)

"Puskesmas [...] Kalau di kita sih SDMnya itu yang kurang." (PPK)

"Biasanya formatnya itu mereka ada juga yang formatnya ga ngambil dari yang kita kirim ke puskesmas [...] Nanti kita evaluasi tuh kok ga sesuai format nanti dibalikin lagi dong ke mereka direvisi lagi." (PPK)

Hasil penelitian ini sejalan dengan penelitian Brooks et al (2020) yang menyatakan bahwa tenaga kesehatan yang bekerja selama pandemi COVID-19 memiliki durasi kerja yang panjang, masif, dan mungkin belum pernah terjadi sebelumnya pada beberapa tenaga kesehatan sehingga menimbulkan implikasi tambahan dalam memicu terjadinya efek psikologis negatif termasuk salah satunya kelelahan emosional. Maka dari itu, Dinas Kesehatan Kota Depok sebaiknya melakukan analisis beban kerja kepada SDM perencana obat untuk mengetahui beban kerja SDM perencana obat selama pandemi COVID-19 dengan menggunakan penilaian tingkat ketelitian, kecepatan maupun konsentrasi kerja dengan alat reaction timer.

\section{Metode}

Metode berupa prosedur tertulis yang digunakan oleh UPTD Farmasi Dinas Kesehatan Kota Depok untuk merencanakan obat yaitu standard operating procedure (SOP) dengan nomor SOP-UPTD PERBEKFAR-01 tentang prosedur perencanaan obat dan perbekalan kesehatan. Pelaksanaan perencanaan obat di UPTD Farmasi Dinas Kesehatan Kota Depok telah disesuaikan dengan SOP yang ada. Dengan adanya prosedur perencanaan secara tertulis, maka harapannya dapat memudahkan koordinasi antar pihak yang terkait dengan perencanaan obat sehingga perencanaan obat dapat terlaksana lebih optimal. Berikut kutipan wawancaranya:

"Kalau perencanaan sih kayaknya udah sesuai ya sama yang ada di SOP kalo untuk perencanaan ya." (PPK)

Hasil penelitian ini sejalan dengan penelitian Sri Juliandayani (2018) bahwa dengan adanya prosedur yang diberikan oleh kepala dinas kepada pihak gudang farmasi akan menjadikan perencanaan obat berjalan dengan baik sesuai dengan prosedur yang telah ditetapkan.

\section{Data}

Pada awalnya UPTD Farmasi Dinas Kesehatan Kota Depok menggunakan Sistem Informasi Pengelolaan Obat (SIPO) untuk melakukan pencatatan dan pelaporan logistik obat, namun pada bulan Januari 2020 sampai dengan Desember 2020 SIPO tersebut masih dalam tahap perbaikan, maka dari itu pencatatan dan pelaporan sementara dilakukan secara manual dengan menggunakan microsoft office excel. Pencatatan dan pelaporan yang dilakukan secara manual menimbulkan beberapa hambatan diantaranya pencatatan dan pelaporan logistik yang belum lengkap, belum tertib, dan tidak tepat waktu. Hal tersebut mengakibatkan hasil rekapitulasi data yang menyimpang atau data outliers sehingga data tersebut dapat meningkatkan standar error yang menjadikan hasil kinerja tidak valid dan tidak akurat, berikut kutipan wawancaranya: (PPK)

"[...] Kalau yang sekarang manual [...]"

"Perhitungan rencana kebutuhan obat Puskesmas sering kali tidak akurat... Menyebabkan ditemukan data yang outliers [...] akibat dari outliers 
ini maka standar error akan meningkat sehingga semakin kecil peluang untuk mendapatkan hasil kinerja yang valid dan akurat." (KAF)

Hasil penelitian ini sejalan dengan penelitian Sri Juliandayani (2018) bahwa datadata yang belum lengkap untuk menyusun rencana kebutuhan obat, akan memengaruhi hasil akhir dari perencanaan yang dilakukan. Maka dari itu, UPTD Farmasi Dinas Kesehatan Kota Depok sebaiknya melakukan uji validitas melalui pengolahan data agar data yang digunakan untuk penyusunan perencanaan obat menjadi lebih akurat.

\section{Anggaran}

Sumber dana untuk memenuhi kebutuhan obat di UPTD Farmasi Dinas Kesehatan Kota Depok yaitu Anggaran Pendapatan dan Belanja Daerah (APBD), Anggaran Pendapatan dan Belanja Negara (APBN), dan Dana Alokasi Khusus (DAK). Anggaran pengadaan obat untuk tahun 2020 sebesar Rp 2.827.884.900 dengan realisasi sebesar Rp 2.827.814.651. Anggaran obat untuk tahun 2020 telah mencukupi untuk membeli berbagai jenis item obat yang perlu diadakan di UPTD Farmasi Dinas Kesehatan Kota Depok. Harapannya dengan anggaran yang telah mencukupi dapat mencapai penggunaan alokasi dana secara berdaya guna dan berhasil guna sehingga ketersediaan obat dapat terjamin untuk memenuhi kebutuhan di Unit Pelayanan Kesehatan Dasar. Berikut kutipan wawancaranya:

"Untuk yang tahun ini sih alhamdulillah, bisa memenuhi sih. Alhamdulillah ngga kurang [...]" (PPK)

Hasil penelitian ini sejalan dengan penelitian Ihsan dkk (2015) bahwa dana yang memadai dari pemerintah sangat menentukan ketersediaan dan keterjangkauan obat esensial oleh masyarakat. Ketersediaan dana untuk pengadaan obat yang sesuai dengan kebutuhan akan mencapai terlaksananya penggunaan obat yang rasional yang pada gilirannya akan meningkatkan mutu pelayanan kesehatan.

\section{Pemilihan Jenis Obat}

Pemilihan jenis obat yang dilakukan oleh UPTD Farmasi Dinas Kesehatan Kota Depok berpedoman pada Formularium Nasional (FORNAS) tahun terakhir, Daftar Obat Essensial Nasional (DOEN), dan mengacu pada daftaran Rencana Kebutuhan Obat (RKO) obat dua tahun terakhir. Dalam melakukan pemilihan jenis obat, ditemukan hambatan yaitu terdapat SDM Perencana Obat Program yang melakukan pemilihan obat dengan dua jenis yang berbeda dan efek terapi yang sama serta salah satu jenis tersebut jumlahnya sedikit. Hal tersebut menjadi suatu hambatan karena untuk obat program APBN tidak dapat dilakukan pengadaan dengan dua macam jika efek terapi obat tersebut sama. Apabila dilakukan pengadaan 2 (dua) jenis obat yang berbeda dapat mengakibatkan tidak efisiennya penggunaan anggaran sehingga dapat merugikan anggaran belanja negara. Berikut kutipan wawancaranya:

"[...] Nah itu kendalanya, kan gabisa gitu ya ada 2 macem alasannya apa mengadakan gitu dari APBN [...] karena itu beresiko dong timbul permasalahan kan ya, karena pembeliannya juga cuma sedikit [...]" (PRKL)

Hasil penelitian ini sejalan dengan penelitian yang dilakukan oleh Widodo dkk (2019) bahwa sulitnya memilih item obat menjadi kendala dalam pemilihan obat, karena pemilihan tidak menggunakan kriteria dasar seleksi pemilihan obat hanya berdasarkan obat generik dari Dinas Kesehatan sehingga masih terdapat duplikasi obat dan pembagian kerja dalam perencanaan obat yang masih perlu diperbaiki lagi. Maka dari itu, UPTD Farmasi Dinas Kesehatan Kota Depok sebaiknya mempertimbangkan beberapa kriteria sebagai acuan dalam pemilihan jenis obat yaitu obat merupakan kebutuhan untuk sebagian besar populasi penyakit, obat memiliki keamanan dan khasiat yang didukung dengan bukti ilmiah, obat memiliki mutu yang terjamin, biaya pengobatan memiliki rasio antara manfaat dan biaya yang baik, paling lengkap data ilmiahnya 
dan farmakokinetiknya menguntungkan, mudah diperoleh dan harga terjangkau sehingga terhindar dari duplikasi dan kesamaan jenis obat.

\section{Kompilasi Penggunaan Obat}

Kompilasi penggunaan obat di UPTD Farmasi Dinas Kesehatan Kota Depok dilakukan dengan cara merekapitulasi data pemakaian obat di Puskesmas yang bersumber dari Laporan Pemakaian dan Lembar Permintaan Obat (LPLPO) Puskesmas. Dalam melakukan kompilasi penggunaan obat, ditemukan beberapa hambatan yaitu pencatatan pemakaian obat yang tertuang dalam LPLPO dilakukan secara manual dan terkadang SDM perencana obat kurang teliti dalam mencatat pemakaian obat, sehingga LPLPO yang diberikan tidak lengkap. Apabila kompilasi penggunaan obat tidak dilakukan dengan LPLPO yang lengkap dan valid akan mengakibatkan hasil rekapitulasi data yang menyimpang dan tidak akurat. Berikut kutipan wawancaranya:

"[...] Sebagian yang punya data yang lengkap mungkin dia akan tenang gitu, tapi kalau yang gak punya, mereka akan pake kirologi." (PPK)

Hasil penelitian ini sejalan dengan penelitian Nandiati (2019) bahwa ketersediaan data yang masih belum lengkap karena masih dalam tahap pembenahan dan perbaikan dan pencatatan masih manual sehingga hal tersebut menyebabkan kesalahan dalam pencatatan. Maka dari itu, UPTD Farmasi Dinas Kesehatan Kota Depok sebaiknya melakukan uji validitas melalui pengolahan data agar penyusunan perencanaan obat lebih akurat.

\section{Perhitungan Kebutuhan Obat}

UPTD Farmasi Dinas Kesehatan Kota Depok menggunakan metode konsumsi dan metode epidemiologi atau morbiditas untuk menghitung kebutuhan obat. Metode konsumsi digunakan untuk menghitung jumlah kebutuhan obat rutin serta metode epidemiologi untuk menghitung jumlah kebutuhan obat program dengan berkoordinasi oleh Penanggungjawab Program Dinas Kesehatan Kota Depok.
Hambatan dalam perhitungan kebutuhan obat diantaranya selama pandemi COVID-19, beberapa obat mengalami penyerapan yang fluktuatif sehingga perlu diatasi dengan melakukan perhitungan kebutuhan obat dengan ketelitian serta kehati-hatian yang tinggi untuk menganalisa kebutuhan obat, serta beberapa sumber daya manusia perencana obat baik Pengelola Obat Puskesmas maupun Penanggungjawab Program Puskesmas terkadang melakukan perhitungan tidak berdasarkan pemakaian rata-rata per bulannya, melainkan dengan hanya memperkirakan jumlah kebutuhan obat yang disebabkan karena beliau tidak memiliki data yang lengkap dan kurang pengetahuan karena belum pernah mengikuti pelatihan terkait perencanaan obat. Berikut kutipan wawancaranya:

"[...]Emang kunjungan ini menurun agak menurun sih, Mbak. Biasanya tuh satu hari itu bisa [...] 200 paling banyak. Tapi selama covid ini cuma 70 pasien [...." (PORJ)

Hasil penelitian ini sejalan dengan penelitian yang dilakukan oleh Sari (2019) bahwa evaluasi penggunaan obat sebelumnya rutin dilakukan tepatnya pada akhir tahun. Evaluasi ini dilakukan agar perhitungan untuk perencanaan tahun berikutnya lebih tepat dan untuk penyesuaian obat yang keluar antara gudang dan apotek. Maka upaya yang telah dilakukan oleh UPTD Farmasi Dinas Kesehatan Kota Depok yaitu mengevaluasi hasil perhitungan kebutuhan obat yang diberikan oleh Pengelola Obat Puskesmas dilakukan dengan ketelitian yang sangat tinggi maka harapannya dapat menyesuaikan antara permintaan dengan kebutuhan riil di pelayanan kesehatan dasar.

\section{Kesesuaian Perencanaan Obat dengan Pedoman}

Perencanaan obat yang dilakukan oleh UPTD Farmasi belum sepenuhnya sesuai dengan pedoman teknis pengadaan obat publik dan perbekalan kesehatan untuk pelayanan kesehatan dasar yakni pada dokumen SK Tim Perencana Obat Terpadu (TPOT), 
penyelenggaraan pertemuan, tahap pemilihan jenis obat dan perhitungan kebutuhan obat serta terdapat faktor yang menyebabkan hasil perencanaan tidak sesuai dengan yang diharapkan dengan dibuktikan oleh terdapatnya obat yang kedaluwarsa dan kekosongan stok obat yang disebabkan oleh faktor di luar sistem. Persentase obat kedaluwarsa adalah sebesar $17,39 \%$ dari total 253 item obat yang tersedia dengan nilai $\mathrm{Rp} 451.668 .145$ serta 3 (tiga) item obat yang kosong (stock out). Berikut kutipan wawancaranya:

"Kalau kondisi yang sekarang itu, yang sekarang terjadi itu, karena memang adanya ini kan [...] covid jadinya penurunannya jauh banget [...]" (PPK)

Jumlah obat kedaluwarsa tidak sesuai dengan standar yang ditetapkan oleh Kemenkes RI (2010) dalam Materi Pelatihan Manajemen Kefarmasian di Instalasi Farmasi Kabupaten/Kota bahwa persentase nilai obat rusak dan kedaluwarsa paling banyak $\leq 2 \%$. Hasil dari presentase obat kedaluwarsa di UPTD Farmasi Dinas Kesehatan Kota Depok masih belum baik dari hasil penelitian yang dilakukan oleh Akbar dkk (2016), Sarwijiyati (2019), Anggraini dan Merlina (2020) dengan presentase berturut-turut sebesar $0,5 \%, 1,85 \%$, $0,33 \%$. Obat kedaluwarsa yang terjadi di UPTD Farmasi Dinas Kesehatan Kota Depok pada tahun 2020 dipengaruhi oleh beberapa faktor. Faktor tersebut meliputi masa kedaluwarsa obat yang pendek, stok obat berlebih, dan penyerapan obat yang berkurang.

Kekosongan stok (stock out) disebabkan karena obat tidak terdapat di $e$-Katalog. Hal ini sejalan dengan penelitian yang dilakukan oleh Muthahara dkk (2018) bahwa pihak dinas kesehatan sudah berusaha memenuhi semua permintaan obat, adapun beberapa obat yang tidak tersedia di puskesmas itu diakibatkan karena pihak dinas kesehatan melakukan pengadaan melalui tender dan $e$-katalog.

Terdapatnya obat kedaluwarsa dengan jumlah yang melebihi standar dan kekosongan obat mengindikasikan bahwa perencanaan obat
UPTD Farmasi Dinas Kesehatan Kota Depok belum dilaksanakan secara efektif dan efisien serta mencerminkan bahwa pengelolaan obat belum terlaksana dengan baik (Kemenkes RI 2010). Dengan adanya obat yang kedaluwarsa dan kekosongan obat dapat menimbulkan dampak yaitu pelayanan kefarmasian tidak dapat berjalan dengan optimal, sehingga menimbulkan ketidakpuasan pasien dalam menjangkau kebutuhan obat di pelayanan kesehatan dasar. Maka dari itu, Dinas Kesehatan Kota Depok sebaiknya melakukan monitoring dan evaluasi terhadap ketersediaan obat di Puskesmas agar temuan obat kedaluwarsa atau kekosongan stok obat dapat diminimalisir.

\section{PENUTUP}

Analisis perencanaan obat di UPTD Farmasi Dinas Kesehatan Kota Depok menunjukan bahwa sumber daya yang tersedia belum sepenuhnya menunjang untuk dilaksanakan perencanaan obat. Akibatnya terdapat hambatan berupa human error yang menyebabkan proses perencanaan obat belum dilaksanakan secara tepat. Selain itu perencanaan obat yang dilakukan belum sepenuhnya sesuai dengan pedoman serta terdapat obat kedaluwarsa dan kekosongan stok obat yang menyebabkan hasil perencanaan tidak sesuai dengan yang diharapkan.

\section{DAFTAR PUSTAKA}

Akbar N.H., Kartinah N., \& Wijaya C. 2016, 'Analisis Manajemen Penyimpanan Obat di Puskemas Se-Kota Banjar Baru', Jurnal Manajemen dan Pelayanan Kefarmasian, vol. 6, no. 24, pp. 255-260.

Anggraini, D., \& Merlina, S. 2020, 'Analisis Sistem Penyimpanan Obat di Instalasi Farmasi Dinas Kesehatan Kabupaten Rokan Hulu Tahun 2018', PHARMACY: Jurnal Farmasi Indonesia (Pharmaceutical Journal of Indonesia), vol. 17, no. 1, pp. 62-70.

Boku, Y., Satibi, S., \& Yasin, N. M. 2019, 'Evaluasi Perencanaan dan Distribusi Obat Program di Dinas Kesehatan Provinsi Sulawesi Tenggara. 
Jurnal Manajemen Dan Pelayanan Farmasi (Journal of Management and Pharmacy Practice), vol. 9 , no. 2, pp. 88-100.

Brooks, S. K., Webster, R. K., Smith, L. E., Woodland, L., Wessely, S., Greenberg, N., \& Rubin, G. J. 2020, 'The psychological impact of quarantine and how to reduce it: rapid review of the evidence', The Lancet, pp. 514523.

Dinas Kesehatan Kota Depok 2019, Profil Kesehatan Kota Depok Tahun 2018, Depok.

Depkes R.I., 2008, Keputusan Menteri Kesehatan RI Nomor 1121 Tahun 2008 Tentang Pedoman Teknis Pengadaan Obat Publik Dan Perbekalan Kesehatan Untuk Pelayanan Kesehatan Dasar, Jakarta.

Ihsan, S., Amir, S. A., \& Sahid, M. 2015, 'Evaluasi Pengelolaan Obat di Instalasi Farmasi Rumah Sakit Umum Daerah Kabupaten Muna Tahun 2014', Pharmauho: Jurnal Farmasi, Sains, dan Kesehatan, vol. 1, no 2.

Juliandayani, T. S. 2018, 'Analisis Perencanaan Obat di Gudang Farmasi Dinas Kesehatan Kotamadya Binjai Tahun 2018', Skripsi, Universitas Sumatera Utara, Medan.

Kemenkes R.I. 2010, Materi Pelatihan Manajemen Kefarmasian di Instalasi Farmasi Kabupaten/Kota, Jakarta.
Lubis, A. S. P. 2017, 'Analisis Manajemen Logistik Obat Di Instalasi Farmasi Dinas Kesehatan Kabupaten Deli Serdang Lubuk Pakam Tahun 2017', Skripsi, Universitas Sumatera Utara, Medan.

Muthahara, M. Jamaluddin S., \& Andri, M. 2018, 'Analisis Sistem Pengelolaan Obat Di Puskesmas Kamonji Kecamatan Palu Barat' Jurnal Kolaboratif Sains vol. 1, no. 1.

Nandiati, N. 2019, 'Analisis Perencanaan Obat di Instalasi Farmasi RSUD dr. Sadikin Pariaman Tahun 2019', Skripsi, Universitas Sumatera Utara, Medan.

Sari, C. M. 2019, 'Analisis Perencanaan Obat di RSUD Deli Serdang Lubuk Pakam Tahun 2018', Skripsi, Universitas Sumatera Utara, Medan.

Sarwijiyati, E. 2019, 'Evaluasi Pengelolaan Obat Kedaluwarsa Di Instalasi Farmasi Kabupaten (IFK) Y', Skripsi, Stikes Duta Gama.

Widodo, M. D., Renaldi, R., \& Andaresta, O. S. 2019. Analisis Sistem Perencanaan Logistik Obat di Puskesmas Simpang Tiga Kota Pekanbaru Tahun 2018. Jurnal Kebijakan Kesehatan Indonesia: JKKI, vol. 8, no. 2, pp 5963. 